\title{
Shapley Value: its Algorithms and Application to Supply Chains
}

\section{El valor de Shapley: sus Algoritmos y Aplicación en Cadenas de Suministro}

DOI: http://dx.doi.org/10.17981/ingecuc.13.1.2017.06

Artículo de investigación. Fecha de Recepción: 16 de octubre de 2016. Fecha de Aceptación: 26 de diciembre de 2016

Daniela C. Landinez-Lamadrid

Fundación Centro de Investigación en Modelación Empresarial del Caribe. Barranquilla (Colombia) dlandinez@fcimec.org

Diana G. Ramirez-Ríos

Rensselaer Polytechnic Institute. New York (Estados Unidos)

Fundación Centro de Investigación en Modelación Empresarial del Caribe. Barranquilla (Colombia)

ramird2@rpi.edu,dramirez@fcimec.org

Dionicio Neira Rodado

Universidad de la Costa. Barranquilla (Colombia)

dneira1@cuc.edu.co

Kevin Parra Negrete

Universidad de la Costa. Barranquilla (Colombia)

kparra7@cuc.edu.co

Johana Patricia Combita Niño

Universidad de la Costa. Barranquilla (Colombia)

jcombita22@gmail.com

Para citar este artículo:

D.C. Landinez-Lamadrid, D. G. Ramirez-Ríos, D. Neira Rodado, K. Parra Negrete and J.P. Combita Niño "Shapley Value: its algorithms and application to supply chains," INGE CUC, vol. 13, no. 1, pp. 61-69, 2017. DOI: http://dx.doi.org/10.17981/ingecuc.13.1.2017.06

\section{Resumen}

Introducción- Los teóricos del juego cooperativos han estudiado la estructura de coalición y los esquemas de pago atribuidos a esas coaliciones. En relación al valor del pago, hay varias maneras de obtener la "mejor" distribución del valor del juego. El concepto de solución o la distribución del valor de recompensa que se mantiene canónicamente para dividir justamente el valor de una coalición se llama Valor de Shapley. Es probablemente el esquema de pago más importante en los juegos cooperativos. La razón por la cual el valor de Shapley ha sido el foco de tanto interés es que representa un acercamiento distinto a los problemas de la interacción estratégica compleja que la teoría del juego intenta resolver.

Objetivo- Este estudio tiene como objetivo hacer una breve revisión bibliográfica de la aplicación del Valor de Shapley para resolver problemas en diferentes campos de cooperación y la importancia de estudiar los métodos existentes para facilitar su cálculo. Esta revisión se centra en la visión algorítmica de la teoría cooperativa de juegos con un énfasis especial en las cadenas de suministro. Adicionalmente se propone un algoritmo para el cálculo del Valor de Shapley y se utilizan ejemplos numéricos para validar el algoritmo propuesto.

Metodología- En primer lugar, se identificaron los algoritmos utilizados para calcular el valor de Shapley. También se identificó los elementos que forman una cadena de suministro. Luego se simula la cooperación entre los miembros de las vías de la cadena de suministro y se calcula el valor de Shapley utilizando el algoritmo propuesto para comprobar su aplicabilidad.

Resultados y Conclusiones- El enfoque algorítmico introducido en este documento no pretende menospreciar las contribuciones hechas hasta ahora, pero tiene la intención de proporcionar una solución directa para problemas de decisión que involucran cadenas de suministro. Una manera eficiente y factible de calcular el valor de Shapley cuando las estructuras de jugador se conocen de antemano proporciona la ventaja de reducir la cantidad de esfuerzo en el cálculo de todas las estructuras de coalición posibles antes del Shapley

Palabras clave- Juegos cooperativos, valor de Shapley, cadena de suministro, competitividad, clúster.

\section{Abstract}

Introduction- Coalitional game theorists have studied the coalition structure and the payoff schemes attributed to such coalition. With respect to the payoff value, there are number ways of obtaining to "best" distribution of the value of the game. The solution concept or payoff value distribution that is canonically held to fairly dividing a coalition's value is called the Shapley Value. It is probably the most important regulatory payoff scheme in coalition games. The reason the Shapley value has been the focus of so much interest is that it represents a distinct approach to the problems of complex strategic interaction that game theory tries to solve.

Objective-This study aims to do a brief literature review of the application of Shapley Value for solving problems in different cooperation fields and the importance of studying existing methods to facilitate their calculation. This review is focused on the algorithmic view of cooperative game theory with a special emphasis on supply chains. Additionally, an algorithm for the calculation of the Shapley Value is proposed and numerical examples are used in order to validate the proposed algorithm.

Methodology- First of all, the algorithms used to calculate Shapley value were identified. The element forming a supply chain were also identified. The cooperation between the members of the supply chain ways is simulated and the Shapley Value is calculated using the proposed algorithm in order to check its applicability.

Results and Conclusions- The algorithmic approach introduced in this paper does not wish to belittle the contributions made so far but intends to provide a straightforward solution for decision problems that involve supply chains. An efficient and feasible way of calculating the Shapley Value when player structures are known beforehand provides the advantage of reducing the amount of effort in calculating all possible coalition structures prior to the Shapley

Keywords- Cooperative games, Shapley value, Supply chain, competitiveness, cluster. 


\section{Introduction}

The free trade philosophy has forced companies throughout the globe to compete with organizations that are bigger and more competitive. This situation has threatened the sustainability of many companies and productive chains [1]. Therefore, many productive chains and companies are forming coalitions in order to be more competitive, hence they are more capable to face foreign competition. Nevertheless, cooperation brings also new challenges to organizations. For example, the introduction of cooperation in supply chain management has increased the importance of existing methods for coordination, operations management and profit allocation according to benefits obtained from each cooperation activity. This coordination is possible through Cooperative game theory, where all players cooperate in order to achieve overall benefits and not affect their own personal benefits [2].

Coalitional game theorists have studied the coalition structure and the payoff schemes attributed to such coalition. With respect to the payoff value, there are number ways of obtaining to "best" distribution of the value of the game. One desirable criterion is fairness: assessing the extent to which each player contributed to the coalition's value. The solution concept or payoff value distribution that is canonically held to fairly divide a coalition's value is called the Shapley Value [3]. Shapley Value is a way to attribute the economic output of a team to the individual members of that team [4]. It is probably the most important regulatory payoff scheme in coalition games [5].

The reason the Shapley value has been the focus of so much interest is that it represents a distinct approach to the problems of complex strategic interaction that game theory tries to solve [6]. Many authors have developed or implemented methods based on the Shapley value to boost cooperation within alliances. For example, Quigley \& Walls [7] proposed a mechanism for obtaining fair prices and ensuring the reliability of negotiation between suppliers. Yu, Dong-Mei, \& Xiao-Min [8] solved the problem of fair and equitable distribution of benefits in an alliance. Xin-Zhong \& Xiao-Fei [9] developed a study to allocate the cost of delivery between suppliers rationally. Yu, et al. [10] applied Shapley Value decomposition and other methods to determine carbon emission reduction target allocation. Liao, et al. [11] conducted a case study on initial allocation of Shanghai carbon emission trading based on Shapley value. Sheng \& Shi [12] presented a cost allocation model for telecommunication infrastructure based on the Shapley Value algorithm. These studies highlight the application of Shapley Value for solving problems in different cooperation fields and the importance of studying existing methods to facilitate their calculation.
This paper is focused on the algorithmic view of cooperative game theory with a special emphasis on supply chains. It is organized as follows: Section 2 introduces the fundamental concepts and principles of the cooperative theory; in Section 3 a number of algorithms found in literature for calculating the Shapley value are reviewed; in Section 4, a numerical example is developed and a Shapley Value algorithm is presented to solve the problem, and Section 5 present conclusions and future research directions.

\section{Literature Review}

Cooperative game theory goes back to John von Neumann (1928) and since then it has been widely studied over the past five decades. Its applications cover a great number of disciplines. Nowadays it has been incorporated in economics, military science, political theory, sociology and ethics theory. Game theory, as part of the rational choice theory, promises to substantially contribute to unification of social disciplines. Ho, Hsu, \& Lin (2011) defined Game Theory as the study of mathematical models of conflict and cooperation between decision-makers characterized by being rational and intelligent subjects. Thus, game theory can be divided into two branches, called non-cooperative and cooperative.

The most widely studied cooperative game model is that of characteristic-function game. This simple model proves to be sufficient to capture the properties of many cooperative scenarios [13]. A cooperative game (or game characteristic function) is specified by a pair $(N, v)$ where $N$ is a set of $n$ agents and $v: 2^{N} \rightarrow \mathrm{R}$ is the characteristic function that assigns a value $v(S)$ to every subset $S \subseteq N$, representing the value that agent in $S$ can obtain and distribute among all coalition members (including himself) if they cooperate (only) with each other [14]

Different approaches for solving cooperative games are found in literature, the most common are presented in the following subsections.

\section{A. Core}

The core is an important concept of coalition games. It combines all the principles that cover what is known as a feasible coalition according to John Nash. Given $S$ is a feasible set, $(u, v)$ the profits that two players would receive if they acted together, $\left(u^{*}, v^{*}\right)$ the minimum value that each player would be willing to accept and $(\bar{u}, \bar{v})$ the cooperation solution, the principles exposed by Nash are:

1. Individual rationality: $(\bar{u}, \bar{v}) \geq\left(u^{*}, v^{*}\right)$

2. Feasibility: $(\bar{u}, \bar{v}) \in S$

3. Pareto optimality: $\left(\bar{u}, v^{-}\right) \in S y(u, v) \geq\left(\bar{u}, v^{-}\right)$, so $(u, v)=\left(u^{*}, v^{*}\right)$ 
4. Independence from irrelevant alternatives: $(\bar{u}, \bar{v})$ $\in T \subset S$ and $(\bar{u}, \bar{v})=\varphi\left(S, u^{*}, v^{*}\right)$, then $(\bar{u}, \bar{v})=\varphi(T$, $\left.u^{*}, v^{*}\right)$ -

5. Independence from linear transformations given a set $T$ extracted from $S$ by the following transformation:

$$
\begin{aligned}
& u^{\prime}=a_{1} u+\beta_{1} \\
& v^{\prime}=a_{2} u+\beta_{2}
\end{aligned}
$$

As $\varphi\left(S, u^{*}, v^{*}\right)=(\bar{u}, \bar{v})$, the following relation is obtained

$$
\varphi\left(T, a_{1} u^{*}+\beta_{1}, a_{2} v^{*}+\beta_{2}\right)=\left(a_{1} \bar{u}+\beta_{1}, a_{2} v^{*}+\beta_{2}\right) .
$$

6. Symmetry. Assume $S$ is a set such that

$$
(u, v) \in S \leftrightarrow(u, u) \in \mathrm{S}
$$

7. Suppose also that $u^{*}=v^{*}$ and that $\varphi\left(S, u^{*}, v^{*}\right)=$ $(\bar{u}, \bar{v})$, then $(\bar{u}=\bar{v})$.

According to Theorem IX. 1.2 [15] it is possible to define a function $\varphi$ in all problems expressed as $\left(S, x^{*}, y^{*}\right)$ satisfying the axioms discussed above. The lemma IX. 1.3 [15] states that for any of the points $(u, v) \in S$, such that $u>u^{*}, v>v^{*}$, there exists a single point $(\bar{u}, \bar{v})$, which maximizes the function $g(u$, $v)=\left(u-u^{*}\right)\left(v-v^{*}\right)$ in the set $S$, for which $u \geq u^{*}$.

According to this, a reasonable allocation plan $\mathrm{x}=$ $\left\{\mathrm{x}_{1}, \mathrm{x}_{2}, \ldots, \mathrm{x}_{\mathrm{n}}\right\}$ should meet the following conditions:

1. $S_{j} \neq \varnothing$

2. $S_{i} \cap S_{j}=0$

3. $\cup_{\in} S_{j}=\mathrm{N}$ (grand coalition)

4. $v(S \cup T) \geq v(s)+v(T)$ for any $S, T \subseteq N$, such that $S \cap T=\varnothing$

$$
\begin{aligned}
& \sum_{i \in S} x_{i} \leq C(S) \\
& \sum_{i \in S} x_{i} \leq C(S)
\end{aligned}
$$

$$
x_{i} \geq 0
$$

\section{B. Nucleolus}

According to Dabbagh \& Sheikh-El-Eslami [16], every cooperative game has one and only one nucleolus, and the nucleolus is in the core unless the core is empty. The aim of using the nucleolus concept is to fairly allocate the total profit, which is jointly earned by all transactions. Defining $\mathrm{k}$ _fu as a binary coefficient that indicates the presence (1) and the absense (0) of unit $u$ in combination of $f$, the obtained profits can be organized as $\Pi \_f$ for $2^{\wedge} \mathrm{U}-1$ combinations. So the Nucleolus can be expressed as:

$$
\begin{gathered}
\begin{array}{c}
\text { Minimize } \varepsilon \\
\text { Subject to }
\end{array} \\
\sum_{u} k_{f u} \Pi u \geq \Pi f-\varepsilon
\end{gathered}
$$

\section{Other solution Concepts}

Once the value that maximizes the benefits of each of the members of the coalition are obtained, it is necessary to determine the adequate distribution of the quantity $v(N)$. This quantity can be represented by the vector $\mathrm{x}$, which must satisfy the principle of efficiency (equation 5).

$$
\sum_{i \in N} x_{i}=v(N)
$$

The majority of the solution concepts, proposed for cooperative games, must satisfy the principle of rational individuality, which establishes that $x_{i}$ $\geq v(\{i\}) \forall i \in N$. The pre-imputations that verify this principle are known as imputations of the game $(N$, $v$ ), denoting as $I(v)$ the set of all of them. This principle, together with the property of superadditivity of coalitions, is accounted by the first solution concept, defined previously as the core of the game. This concept of solution was introduced by Gillies and is defined as the set $C(v)=x \in R^{n}: x(N), x(S) \geq v(S)$, $\forall \mathrm{S} \in 2^{n}$,

Where,

$$
x(S)=\sum_{i \in N} x_{i} y x(\varnothing)=0 .
$$

(The core of the game could be empty)

Another used approach is the concept of Kernel solution. In this concept agents are organized into a set of coalitions $C=\{C i\}$ and their surpluses are calculated as shown in Equation 6.

$$
e(C)=v(C)-\sum_{A i \in C} u^{i}
$$

Where, $u^{i}$ is the payoff of agent $i$ and $v(C)$ is the payoff that the whole coalition obtains.

The maximum surplus $S_{A B}$ of agent A on agent B, considering the coalition configuration is defined in equation 7 .

$$
\begin{aligned}
& S_{A B}=\max _{C\left|A^{i} \cdot C, B \notin C\right|} e(\mathrm{C}) \\
&
\end{aligned}
$$

Agent A overcomes agent B if $S_{A B}>S_{B A}$ and $u^{B}>$ $v(B)$. If neither of them overcomes the other, then they are in equilibrium (i.e. one of the following conditions must be met for equilibrium):

1. $S_{A B}=S_{A B}$

2. $S_{A B}>S_{B A} y u^{B}=v(B)$

3. $S_{A B}>S_{B A} y u^{A}=v(A)$

A Kernel Stable Coalition (K-stable) is a set of coalitional configurations, such that each pair of agents within the same coalition is in equilibrium. The Kernel is a type of solution that uses the surplus of each of the $S \subset N$ sub-sets of a set of $S$ players. Is defined by of the following equation:

$$
\theta k(x)=e\left(S_{k}, x\right)
$$


Being $\mathrm{S}_{1}, \mathrm{~S}_{2}, \ldots, S_{2}{ }^{n}$ subsets of $N$, ordered according to the following relation:

$$
e\left(S_{k}, x\right) \geq e\left(S_{\mathrm{k}+1}, x\right)
$$

The order established in (9) indicates how payment vectors, $X$, are assigned to the different subsets. The core of the game, $v$, on a set $(X)$, is a set $v(X)$ defined in equation 9 .

$$
v(X)=\left\{x \mid\left\{\begin{array}{l}
x \in X \\
\text { si } y \in X, \text { ent. } x \leq y
\end{array}\right\}\right.
$$

But none of these concepts of solution prevented core from being empty. However, Shapley introduced the concept of balanced coalitions and balanced play to determine whether or not the game has an empty core.

Given a set $(N, v)$, a collection $\left\{S_{1}, S_{2}, \ldots, S_{m}\right\}$ of the subset of $N$, distinct and non-empty, is said to be balanced on $N$ if there are positive numbers $\left\{a_{1}, a_{2}\right.$, ..., $\left.a_{\mathrm{m}}\right\}$ - called weights - such that for all $i \in N$,

$$
\sum_{\left\{j i \in S_{j}\right\}} a_{j}=1
$$

If for any balanced solution on $N$, it is verified that, $\sum_{j=1}^{m} a_{j} v\left(S_{j}\right) \leq v(N)$, then the set $(N, v)$ is balanced.

Two other solution concepts are the stable sets of Von Neumann and the negotiation set of Aumann and Maschler. These concepts give solution to cooperative games with transferable gains (utility) when the sub-set of the imputation set is not empty. There are also other proposed solution concepts such as the Shapley Value and the Banzhaf-Coleman value, which assign each player a single element of the set of pre-allocations.

Recently, one of the most recognized solution concepts in the literature has been the Shapley value, since it is one of the few values that meets all the properties that the preimputation vector for any coalition must have in a cooperative game. Shapley came to this value in an axiomatic way, i.e. for each value of the game $v$, there is an n-vector, $\emptyset_{i}(v)$, that fulfills the following axioms:

1. If $x x$ is a carrier of $x x$, then:

$$
\sum_{S} \emptyset i(v)=v(S)
$$

2. For each permutation $\Pi^{* *}$, e $i \in N$,

$$
\emptyset_{\Pi(i)} \Pi v=\emptyset_{i} v
$$

3. If $u$ and $v$ are any two games,

$$
\emptyset_{i} u\left|+\mathrm{v}=\emptyset_{i} u\right|+\emptyset_{i} v \mid
$$

Then the Shapley value is obtained with this formula (12):

$$
\emptyset_{i}(v)=\sum_{S \in N: i \in S} \frac{(S-1) !(n-S) !}{\mathrm{n} !}(S)-v(S-\{i\})
$$

When these two conditions are met it is called the core. In practice, it is possible for the core to be empty, because of the contradictory between the cost allocated to a league and the total cost [1]

\section{Shapley Value}

Shapley value is able to calculate each player's contribution to possible coalitions in a very precise way. Nevertheless, some authors highlighted their computational complexity as it is observed from Equation 12 that the way of calculating the value is only determined after calculating all possible coalitions, which for $n$ number of players, it is $2^{n}-1$. Thus, a number of researchers have developed improved algorithms for dealing with this complexity.

Fatima, et al. [2] developed a new approximation algorithm to calculate the Shapley value in votes games after discovering its computational complexity, this method uses a technique of randomization and presents a complexity in real time. In comparison to Owen method, this algorithm proved to be better in terms of approximation error.

Hong \& Yanhong [3] provided a modified algorithm to improve faults in Shapley Value algorithm by establishing a condition that ensures that the benefits of participants are not reduced if the alliance does not want to disintegrate and that the additional benefits are rationally distributed. As result of this, was obtained that the new method maintains the stability of the alliance and also reaches the whole optimum.

Kim [4] proposed an online wireless network routing algorithm for the energy efficiency and reliability of the network, based on a cooperative game model. The added value of the scheme developed is related to the ability to maintain energy efficiency as high as possible, the ability to respond to current network conditions for adaptive management, the dynamically adjustable approach taking into account system information in the execution time, and the ability to achieve load balancing for real network operations.

Chao-hui [5], developed a new revenue allocation strategy based on the Shapley method principle, they took into account a risk coefficient, and an investment to improve the effects of the profits allocation, allowing the distribution of benefits reasonably and ensuring the persistence of the alliance and stability in the supply chain cooperation. This research was motivated by the fact that the original algorithm cannot fully mobilize the enthusiasm of partners, which prevent that cooperation in supply chain management being totally optimal.

Cui, et al. [6] presented an algorithm to improve the Shapley value in concurrent delay claim, which can be applied in construction field. The algorithm developed is palliative, and in this, time delay responsibility is allotted to each single responsible activity by Shapley Value, and then allotted between 
the owner and the contractor in each single responsible activity.

$\mathrm{Xu}$, et al. [7] raised a modification of the classical Shapley algorithm in order to strengthen technology alliances, mainly in RFID and find equal benefits under the generated alliances. The modification allowed the authors to calculate the Shapley value for a cooperative game and to obtain a payment function.

Muros, et al. [8] presented an alternative way for considering constraints on the Shapley value by using a more computationally efficient design. The new method employs a one-step design algorithm that allows to reduce the computational burden.
Castro, et al. [9] proposed a refinement of the polynomial method based on sampling theory proposed by Castro et al. (2009) to estimate the Shapley value for cooperative games, this method employ random sampling with optimum allocation in order to reduce the variance. The proposed algorithm obtained improvements in situations where the variabilities in the marginal contributions of each player are very different, or in those situations where the variability of the marginal contributions depends greatly on each player's arrival position.

The most important improvements of these papers are presented in Table 1.

TABLe 1. Improvements DEVeloped.

\begin{tabular}{|c|c|c|}
\hline Research & Application & Description \\
\hline $\begin{array}{l}\text { Fatima, } \\
\text { Wooldridge, \& } \\
\text { Jennings [2] }\end{array}$ & - Voting games & $\begin{array}{l}\text { - Aproximation algorithm based on randomization. } \\
\text { - Time complexity linear in the number of players. } \\
\text { - Lower approximation error. }\end{array}$ \\
\hline $\begin{array}{l}\text { Hong \& } \\
\text { Yanhong [3] }\end{array}$ & · General & $\begin{array}{l}\text { The objective is improve the shortcommings of the Shapley value algorithm. } \\
\text { - The new method keeps the stability of the aliance and equitable distribution. }\end{array}$ \\
\hline $\operatorname{Kim}[4]$ & $\begin{array}{l}\text { Energy efficiency, } \\
\text { network reliability. }\end{array}$ & $\begin{array}{l}\text { Adaptive online routing algorithm. } \\
\text { Each node in algorithm is capable of independently adapting its operation and } \\
\text { can quickly response to the current network environment changes. }\end{array}$ \\
\hline Chao-hui, [5] & - General. & $\begin{array}{l}\text { The modified method considers risk and investment coefficiece to improve the } \\
\text { effects in the revenue allocation. }\end{array}$ \\
\hline Cui, et, al. [6] & $\begin{array}{l}\text { Time claim in } \\
\text { concurrent delay. } \\
\text { Construction claim } \\
\text { events. }\end{array}$ & $\begin{array}{l}\text { Ameliorative algorithm for Shapely Value method. } \\
\text { The time delay responsibility is allotted to each single responsible activity, and } \\
\text { then allotted between the owner and the contractor in each single responsible } \\
\text { activity by means of fuzzy comprehensive evaluation method. }\end{array}$ \\
\hline $\begin{array}{l}\text { Xu, Yang \& } \\
\text { Wang [7] }\end{array}$ & $\begin{array}{l}\text { - RFID technology } \\
\text { alliance. }\end{array}$ & $\begin{array}{l}\text { Payoff function of cooperative games with fuzzy coalitions. } \\
\text { The improved method is more practical to the cooperative alliance operations. } \\
\text { - The profit allocation for technology alliance is more reasonable. }\end{array}$ \\
\hline Muros [8] & $\begin{array}{l}\text { Distributed coalitional } \\
\text { schemes. }\end{array}$ & $\begin{array}{l}\text { - Inclusion of Shapley constraints in the design procedure that reduces the } \\
\text { computational burden. }\end{array}$ \\
\hline $\begin{array}{l}\text { Castro, et } \\
\text { al [9] }\end{array}$ & $\begin{array}{l}\text { Symmetric and non- } \\
\text { symmetric voting } \\
\text { game, Airport game, } \\
\text { Shoes game, Minimum } \\
\text { spanning tree game. }\end{array}$ & $\begin{array}{l}\text { Polynomial method based on sampling theory. } \\
\text { Stratified random sampling with optimum allocation in order to reduce the } \\
\text { variance. }\end{array}$ \\
\hline
\end{tabular}

Source: Authors.

Table 2. Basic data of Companies in the Coalition.

\begin{tabular}{|c|c|c|c|}
\hline Companies & Net Profit inU\$ & \% tolerable price reduction & Expected Profit in U\$ \\
\hline PC1 & 25000 & 0,03 & 10000 \\
\hline PC2 & 15000 & 0,1 & 5000 \\
\hline PC3 & 20000 & 0,2 & 8000 \\
\hline PC4 & 14000 & 0,05 & 5000 \\
\hline PC5 & 22000 & 0,1 & 7000 \\
\hline PC6 & 24000 & 0,1 & 9000 \\
\hline
\end{tabular}

Source: Authors. 


\section{Proposed Algorithm Applicable to Supply Chains}

An algorithm to calculate the Shapley Value is proposed in this subsection. This algorithm provides improvements in efficiency as a result of a strategy to reduce complexity of forming all possible coalitions in the game. In the case of supply chains, the structure of these chains are known beforehand and a set of feasible coalitions are obtained. This enables the algorithm to reduce the number of coalitions significantly. This algorithm was introduced as a subroutine of a more general strategic characterization of businesses in the supply chain. The output of this algorithm provides the value attributed to each business (ie. profit, costs, inventory, prices, investments). A case study that consideres this general characterization for the furniture business supply chain was developed by Ramirez-Rios et al [10]. (Fig. 1)

\section{Numerical Example}

To illustrate how the proposed algorithm works, a simulated scenario was assumed. In this particular case this scenario was proposed as a hypothetical case provided in a field survey developed to a number of businesses from the furniture industry cluster in a particular region of Colombia (Barranquilla). The statement provided to the respondents were as follows:

"In order to access to new high volume markets, the furniture cluster asks you to collaborate with the coalition by reducing the prices of your products. How much were you disposed to reduce your sale prices in order to gain this new market?"

Clearly the answer of this question depends on many aspects. Therefore, in order to test the scenario, it was necessary in first place to classify the companies according to the echelon they correspond to, in the furniture value chain. This value chain was divided in three echelons as follows:

1. Suppliers: This group of companies included all the suppliers of the furniture producer companies. Raw material such as wood, fabric, hardware, among others are provided by this echelon to the producer's echelon.

2. Producers: This group of companies included all the furniture producers. The products of these companies are for example beds, dining room furniture, RTA furniture, and others.

3. Marketers: In this group are included all the companies that trade the furniture with the final costumer. These companies have exhibitions, financial incentive for the customers, and all the rest of the necessary conditions for and adequate final costumer commercialization and service.

The presence of these three echelons makes it possible the occurrence of two type of coalitions:

1. Intra-echelon cooperation: In this cooperation scheme the actors of a particular echelon are collaborating with their peers in the game.

2. Inter-echelon cooperation: In this cooperation scheme the actors of a particular echelon are collaborating with actors of a different echelon.

In the simulated scenario it was assumed that the type of collaboration that took place is intraechelon collaboration. The scenario was simulated with six companies that were willing to cooperate. Table 2 shows the relevant data for this scenario, for each one of the six companies. The data related with their present profit, expected profit, and allowed price reduction are crucial to find the expected benefits of each player considering the different possible coalitions. For example, player PC1 can form a coalition with PC2. This coalition had a game value associated. In this particular case the coalition game value is related with the total ex-

Algorithm SV-SC

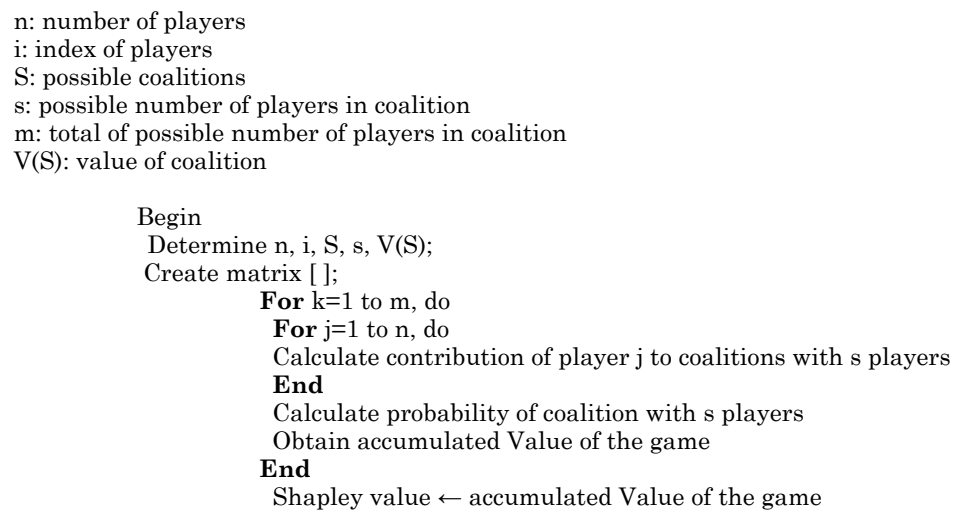

End

Fig. 1. Proposed algorithm pseudocode. Source: Authors. 
Table 3. Game characteristic function.

\begin{tabular}{|c|c|c|c|c|c|}
\hline \multicolumn{6}{|c|}{ GAME CHARACTERISTIC FUNCTION RESULTS $\left(\mathrm{n}_{1}, \mathrm{v}\right)$} \\
\hline COALITION & GAME VALUE & COALITION & GAME VALUE & COALITION & GAME VALUE \\
\hline $\mathrm{v}(\{\mathrm{P} 1\})$ & 25000 & v(\{P1,P2,P3\}) & 81200 & v(\{P1,P2,P3,P5\}) & 109540 \\
\hline $\mathrm{v}(\{\mathrm{P} 2\})$ & 15000 & $\mathrm{v}(\{\mathbf{P} 1, \mathbf{P} 2, \mathbf{P} 4\})$ & 72380 & $\mathrm{v}(\{\mathrm{P} 1, \mathrm{P} 2, \mathrm{P} 3, \mathrm{P} 6\})$ & 113480 \\
\hline $\mathrm{v}(\{\mathbf{P} 3\})$ & 20000 & $\mathrm{v}(\{\mathrm{P} 1, \mathrm{P} 2, \mathrm{P} 5\})$ & 82140 & $\mathrm{v}(\{\mathrm{P} 1, \mathrm{P} 2, \mathrm{P} 4, \mathrm{P} 5\})$ & 100720 \\
\hline $\mathbf{v}(\{\mathbf{P} 4\})$ & 14000 & $\mathrm{v}(\{\mathrm{P} 1, \mathrm{P} 2, \mathrm{P} 6\})$ & 86080 & $\mathrm{v}(\{\mathrm{P} 1, \mathrm{P} 2, \mathrm{P} 4, \mathrm{P} 6\})$ & 104660 \\
\hline $\mathrm{v}(\{\mathrm{P} 5\})$ & 22000 & $\mathrm{v}(\{\mathrm{P} 1, \mathrm{P} 3, \mathrm{P} 4\})$ & 80230 & $\mathrm{v}(\{\mathrm{P} 1, \mathrm{P} 2, \mathrm{P} 5, \mathrm{P} 6\})$ & 114420 \\
\hline $\mathrm{v}(\{\mathrm{P} 6\})$ & 24000 & $\mathrm{v}(\{\mathbf{P} 1, \mathbf{P} 3, \mathbf{P} 5\})$ & 89990 & v(\{P1,P3,P4,P5\}) & 108570 \\
\hline $\mathrm{v}(\{\mathrm{P} 1, \mathrm{P} 2\})$ & 53800 & $\mathrm{v}(\{\mathrm{P} 1, \mathrm{P} 3, \mathrm{P} 6\})$ & 93930 & v(\{P1,P3,P4,P6\}) & 112510 \\
\hline $\mathrm{v}(\{\mathbf{P} 1, \mathbf{P} 3\})$ & 61650 & $\mathrm{v}(\{\mathbf{P} 1, \mathbf{P} 4, \mathbf{P} 5\})$ & 81170 & $\mathrm{v}(\{\mathrm{P} 1, \mathrm{P} 3, \mathrm{P} 5, \mathrm{P} 6\})$ & 122270 \\
\hline $\mathrm{v}(\{\mathrm{P} 1, \mathbf{P} 4\})$ & 52830 & $\mathrm{v}(\{\mathrm{P} 1, \mathbf{P} 4, \mathbf{P} 6\})$ & 85110 & $\mathrm{v}(\{\mathrm{P} 1, \mathrm{P} 4, \mathrm{P} 5, \mathrm{P} 6\})$ & 113450 \\
\hline $\mathrm{v}(\{\mathrm{P} 1, \mathrm{P} 5\})$ & 62590 & $\mathrm{v}(\{\mathrm{P} 1, \mathrm{P} 5, \mathrm{P} 6\})$ & 94870 & $\mathrm{v}(\{\mathrm{P} 2, \mathrm{P} 3, \mathrm{P} 4, \mathrm{P} 5\})$ & 92450 \\
\hline$v(\{P 1, P 6\})$ & 66530 & v(\{P2,P3,P4\}) & 64550 & $\mathrm{v}(\{\mathrm{P} 2, \mathrm{P} 3, \mathrm{P} 4, \mathrm{P} 6\})$ & 96350 \\
\hline $\mathrm{v}(\{\mathrm{P} 2, \mathrm{P} 3\})$ & 44500 & v(\{P2,P3,P5\}) & 71300 & v(\{P2,P3,P5,P6\}) & 101900 \\
\hline $\mathrm{v}(\{\mathrm{P} 2, \mathrm{P} 4\})$ & 37550 & v(\{P2,P3,P6\}) & 75100 & $\mathrm{v}(\{\mathrm{P} 2, \mathrm{P} 4, \mathrm{P} 5, \mathrm{P} 6\})$ & 97250 \\
\hline $\mathrm{v}(\{\mathrm{P} 2, \mathrm{P} 5\})$ & 45300 & $\mathrm{v}(\{\mathrm{P} 2, \mathrm{P} 4, \mathbf{P} 5\})$ & 65450 & $\mathrm{v}(\{\mathrm{P} 3, \mathrm{P} 4, \mathrm{P} 5, \mathrm{P} 6\})$ & 105000 \\
\hline$v(\{P 2, P 6\})$ & 49100 & $\mathrm{v}(\{\mathrm{P} 2, \mathrm{P} 4, \mathrm{P} 6\})$ & 69350 & v(\{P1,P2,P3,P4,P5\}) & 128120 \\
\hline $\mathrm{v}(\{\mathrm{P} 3, \mathbf{P} 4\})$ & 45300 & v(\{P2,P5,P6\}) & 75900 & $\mathrm{v}(\{\mathrm{P} 1, \mathrm{P} 2, \mathrm{P} 3, \mathrm{P} 4, \mathrm{P} 6\})$ & 132060 \\
\hline $\mathrm{v}(\{\mathrm{P} 3, \mathrm{P} 5\})$ & 52800 & $\mathrm{v}(\{\mathrm{P} 3, \mathbf{P} 4, \mathbf{P} 5\})$ & 73200 & $\mathrm{v}(\{\mathbf{P 1 , P 2 , P 3 , P 5 , P 6 \} )}$ & 141820 \\
\hline $\mathrm{v}(\{\mathrm{P} 3, \mathrm{P} 6\})$ & 56600 & $\mathrm{v}(\{\mathrm{P} 3, \mathbf{P} 4, \mathrm{P} 6\})$ & 77100 & $\mathrm{v}(\{\mathrm{P} 1, \mathrm{P} 2, \mathbf{P} 4, \mathrm{P} 5, \mathrm{P} 6\})$ & 133000 \\
\hline $\mathrm{v}(\{\mathrm{P} 4, \mathrm{P} 5\})$ & 46200 & $\mathrm{v}(\{\mathrm{P} 3, \mathrm{P5}, \mathrm{P} 6\})$ & 83400 & v(\{P1,P3,P4,P5,P6\}) & 140850 \\
\hline $\mathrm{v}(\{\mathrm{P} 4, \mathrm{P} 6\})$ & 50100 & $\mathrm{v}(\{\mathrm{P} 4, \mathrm{P} 5, \mathrm{P} 6\})$ & 78000 & v(\{P2,P3,P4,P5,P6\}) & 124250 \\
\hline $\mathrm{v}(\{\mathrm{P} 5, \mathrm{P} 6\})$ & 57400 & $\mathrm{v}(\{\mathrm{P} 1, \mathrm{P} 2, \mathrm{P} 3, \mathrm{P} 4\})$ & 99780 & v(\{P1,P2,P3,P4,P5,P6\}) & 160400 \\
\hline
\end{tabular}

Source: Authors.

pected profit for the coalition. In the case of PC1, if it faces the scenario by its own its earnings will remain the same (U\$25,000). The same situation for PC2, its profit will remain the same (U\$ 15000) if it works by its own. But if they work together they will be able of increasing their profit. In the case of PC1 its profit will grow U\$ 10,000, and for PC2 the profit growth will be of $\mathrm{U} \$ 5,000$. In the case of 6 players there are 6 possible coalitions.

The number of coalitions can be discriminated as follows:

1. Coalitions of 1 player ( 6 possibilities)

2. Coalitions of 2 players (15 possibilities)

3. Coalitions of 3 players (20 possibilities)

4. Coalitions of 4 players (14 possibilities)

5 . Coalitions of 5 players ( 6 possibilities)

6. Coalitions of 6 players ( 1 possibility), this one is known as the great coalition.
In Table 3 the game characteristic function of this particular situation can be obtained by represented for each coalition in the structure.

For example in the case of coalition between players CP1 and CP2 de value of the game v(\{P1,P2 $\})$ is calculated considering the lesser tolerable price reduction for the sum of the present profits of the two companies. The resulting value of this operation is added to the expected additional profit for both companies. In the particular case of $\mathrm{v}(\{\mathrm{P} 1, \mathrm{P} 2\})$ the lesser price reduction is $3 \%$, and the present profit is US 25000 for CP1 and US 15000 for CP2. The sum of these two values affected by the reduction of $3 \%$ amounts US 38800. Finally, the expected additional profit is added to this value obtaining the value of US 53800. Similar calculations are made in order to estimate the game value for each coalition, no matter the number of members forming them. 
Once the game value for all the coalitions is calculated the Shapley value is estimated. In this case the calculation was done manually and consolidated in table 4.

In Table 4, rows represent the players, for example row 1 represents company $\mathrm{CP} 1$ and row 3 represents company CP3. Columns represent the size of coalitions. For instance, column number one represents coalitions of size 1 and column 6 represents coalition with 6 players. This table shows the contribution of each player to the coalition of the different sizes in which it participates. For example the value in row number 1 and column number 2 is calculated adding the game value of all the coalitions of size two in which player one is included $(\mathrm{v}(\{\mathrm{P} 1, \mathrm{P} 2\}), \mathrm{v}(\{\mathrm{P} 1, \mathrm{P} 3\}), \mathrm{v}(\{\mathrm{P} 1, \mathrm{P} 4\}), \mathrm{v}(\{\mathrm{P} 1, \mathrm{P} 5\})$, $\mathrm{v}(\{\mathrm{P} 1, \mathrm{P} 6\}))$. To this big sum the individual game values of the other players are subtracted $(\mathrm{v}(\{\mathrm{P} 2\})$, $\mathrm{v}(\{\mathrm{P} 3\}), \mathrm{v}(\{\mathrm{P} 4\}), \mathrm{v}(\{\mathrm{P} 5\}), \mathrm{v}(\{\mathrm{P} 6\}))$, obtaining the value of US 202400. This value is the total contribution of player 1 (CP1) to all the possible coalitions of size 2 that involves $\mathrm{CP} 1$ (player 1).

On the other hand, the row $\mathrm{P}(\mathrm{j})$ indicates the probability of forming coalitions of a particular size. The value of the game for each player including all the coalition is obtained by the multiplication of the player row and $\mathrm{P}(\mathrm{j})$ row. In the case of player 1 the obtained value is US 35173. This procedure is the same for the rest of the players, obtaining the value 160.400 . This value is the value of the great coalition. It is important to point that this is the expected value of all the possibilities but it is useful in order to make a decision to split the benefits of coalitions between its members, knowing the proportion of participation of each player in the total value.

\section{VII.Conclusions and Future Research Directions}

It is important to recognize the relevance cooperation has gained worldwide considering the free trade policies that encourage companies to make coalitions in order to reduce their costs (transportation, inventory, etc), and also in order to increase customer satisfaction by sharing resources to cover warranties, etc. For example, car dealers of different brands share their maintenance workshops, to give appropriate service to their customers.

Cooperative game theory is a field with great opportunities to do research in order to develop tools that help managers, and governments make decisions. In this sense, it is important to continue the search for better ways to make the calculation of the Shapley value. On the other hand, it is worth noting the complexity involved in its calculation and that there exist a number of algorithms developed to date that try to tackle this complexity. The algorithmic approach introduced in this paper does not wish to belittle the contributions made so far but intends to provide a straightforward solution for decision problems that involve supply chains. An efficient and feasible way of calculating the Shapley Value when player structures are known beforehand provides the advantage of reducing the amount of effort in calculating all possible coalition structures prior to the Shapley Value calculation.

The increasing trend in cooperation and sharing economies faced in this era have forced companies to perform significant changes in their business model and organizational structure. It is considered essential to still preserve the know-how but even more important to share information to their suppliers,

Table 4. Consolidated data for the calculation of the Shapley value.

\begin{tabular}{|c|c|c|c|c|c|c|c|}
\hline \multicolumn{8}{|c|}{ Contribution coalitions formed by $\mathrm{j}$ palyers } \\
\hline $\begin{array}{l}\text { Player i in } \\
\text { each coalition }\end{array}$ & 1 & 2 & 3 & 4 & 5 & 6 & $\mathrm{ji}(\mathrm{v})$ \\
\hline 1 & $\$ 25.000,00$ & $\$ 202.400,00$ & $\$ 362.250,00$ & $\$ 366.050,00$ & $\$ 182.900,00$ & $\$ 36.150,00$ & $\$ 35.173,33$ \\
\hline 2 & $\$ 15.000,00$ & $\$ 125.250,00$ & $\$ 191.450,00$ & $\$ 193.550,00$ & $\$ 97.450,00$ & $\$ 19.550,00$ & $\$ 19.598,33$ \\
\hline 3 & $\$ 20.000,00$ & $\$ 160.850,00$ & $\$ 268.600,00$ & $\$ 271.400,00$ & $\$ 136.600,00$ & $\$ 27.400,00$ & $\$ 26.815,00$ \\
\hline 4 & $\$ 14.000,00$ & $\$ 125.980,00$ & $\$ 196.270,00$ & $\$ 196.830,00$ & $\$ 96.670,00$ & $\$ 18.580,00$ & $\$ 9.403,33$ \\
\hline 5 & $\$ 22.000,00$ & $\$ 166.290,00$ & $\$ 277.460,00$ & $\$ 280.540,00$ & $\$ 141.260,00$ & $\$ 28.340,00$ & $\$ 27.941,67$ \\
\hline 6 & $\$ 24.000,00$ & $\$ 183.730,00$ & $\$ 316.320,00$ & $\$ 319.680,00$ & $\$ 160.920,00$ & $\$ 32.280,00$ & $\$ 31.468,33$ \\
\hline $\mathrm{P}(\mathrm{j})$ & 0,166666667 & 0,033333333 & 0,016666667 & 0,016666667 & 0,033333333 & 0,016666667 & $\$ 160.400$ \\
\hline$\frac{(\mathrm{s}-1) !(\mathrm{n}-\mathrm{s}) !}{\mathrm{n} !}$ & \multicolumn{7}{|c|}{$\phi_{i}(v)=\sum_{\{S \in N: i \in S\}} \frac{(S-1) !(n-S) !}{n !}(v(S)-v(S-\{i\}))$} \\
\hline
\end{tabular}

Source: Authors. 
distributers and other actors of the supply chain. Future directions to this research involve studying other forms of cooperation and introducing new applications as a way of evidencing the need for cooperation in the different industries. Not only the supply chain but also other forms of cooperation can be introduced in the organization (i.e, operations, transportation logistics, innovation processes, design, and knowledge management). Until now cooperation has enabled companies face the issues that come with globalization and new markets, thus a fast and robust decision-making tool must be provided.

\section{Funding}

This research was funded by COLCIENCIAS, through the project 2333-6694-6964 entitled: "Diseño y desarrollo de un sistema de información para la valoración estratégica y financiera de las empresas que desean cooperar en un clúster, basada en el valor de Shapley". This work was developed by the research groups Producom and SimOpt from Universidad de la Costa (CUC) and Fundación Centro de Investigación en Modelación Empresarial del Caribe (FCIMEC), respectively.

\section{References}

[1] D. Neira Rodado, J. W. Escobar, R. G. García-Cáceres and N. A. Andrés, "A mathematical model for the product mixing and lot-sizing problem by considering stochastic demand," International Journal of Industrial Engineering Computations, no. 8, pp. 237-250, 2017.

[2] A. Baykasoğlu and B. K. Özbel, "Cooperative interval game theory and the grey Shapley value approach for solving the maximun flow problem," in XIV International Logistics and Supply Chain Congress, Izmir, Turkey , 2016.

[3] A. Fréchette, L. Kotthoff, T. P. Michalak, T. Rahwan, H. H. Hoos and K. Leyton-Brown, "Using the Shapley Value to Analyze Algorithm Portfolios," AAAI, pp. 3397-3403, 2016.

[4] A. Owen and C. Prieur, "On Shapley value for measuring importance of dependent inputs," 2016.

[5] T. P. Michalak, K. V. Aadithya, P. L. Szczepanski, B. Ravindran and N. R. Jennings, "Efficient computation of the Shapley value for game-theoretic network centrality," Journal of Artificial Intelligence Research, vol. 46, pp. 607-650, 2013.

[6] R. Aumann and R. Myerson, "Endogenous formation of links between players and coalitions: an application of the Shapley value," in The Shapley Value, Cambridge University, 1988, pp. 175-191.

[7] J. Quigley and L. Walls, "Trading reliability targets within a supply chain using Shapley's value," Reliability Engineering \& System safety, vol. 92, no. 10, pp. 1448-1457, 2007. https://doi.org/10.1016/j.ress.2006.09.019

[8] W. Yu, C. Dong-mei and Z. Xiao-min, "Study on mechanism of profit allocation in virtual enterprise based on shapley value considering harmony degree," in 16th International Conference on Industrial Engineering and Engineering Management, IE\&EM'09, Beijing, China, 2009. https://doi. org/10.1109/icieem.2009.5344540

[9] B. Xin-zhong and L. Xiao-fei, "Cost Allocation of Integrated Supply Based on Shapley Value Method," in International Conference on Intelligent Computation Technology and Automation (ICICTA), Beijing, China, 2010.
[10] S. Yu, Y. M. Wei and K. Wang, "Provincial allocation of carbon emission reduction targets in China: an approach based on improved fuzzy cluster and Shapley value decomposition,” Energy Policy, vol. 66, pp. 630-644, 2014. https:// doi.org/10.1016/j.enpol.2013.11.025

[11] Z. Liao, X. Zhu and J. Shi, "Case study on initial allocation of Shanghai carbon emission trading based on Shapley value," Journal of Cleaner Production, vol. 103, pp. 338-344, 2015. https://doi.org/10.1016/j.jclepro.2014.06.045

[12] H. Sheng and H. Shi, "Research on Cost Allocation Model of Telecom Infrastructure Co-construction Based on Value Shapley Algorithm," International Journal of Future Generation Communication and Networking, vol. 9, no. 7, pp. 165-172, 2016. https://doi.org/10.14257/ijfgcn.2016.9.7.16

[13] G. Chalkiadakis, E. Elkind and M. Wooldridge, "Cooperative game theory: Basic concepts and computational challenges," IEEE Intelligent Systems, vol. 3, pp. 86-9, 2012. https://doi.org/10.1109/MIS.2012.47

[14] Y. Li and V. Conitzer, "Cooperative Game Solution Concepts that Maximize Stability under Noise," AAAI, pp. 979-985, 2015

[15] G. Owen, Game Theory, 3rd Edition ed. ed., San Diego: Academic Press, 1995, p. 192

[16] S. R. Dabbagh and M. K. Sheikh-El-Eslami, "Risk-based profit allocation to DERs integrated with a virtual power plant using cooperative Game theory," Electric Power Systems Research, vol. 121, pp. 368-378, 2015. https://doi. org/10.1016/j.epsr.2014.11.025

[17] B. Xinzhong, W. Yanfang and S. Ying, "Cost allocation model and its solution about inter-organizational cooperation based on game theory," in 6th IEEE Conference on Industrial Electronics and Applications, Beijing, China, 2011. https://doi.org/10.1109/iciea.2011.5975585

[18] S. S. Fatima, M. Wooldridge and N. R. Jennings, "A linear approximation method for the Shapley value," Artificial Intelligence, vol. 172, no. 14, pp. 1673-1699, 2008. https://doi. org/10.1016/j.artint.2008.05.003

[19] H. Hong and W. Yanhong, "The optimization study on profit allocation among partners in supply chain alliance based on the Shapley Value," in Control and Decision Conference, Yantai, Shandong, China, 2008. https://doi.org/10.1109/ ccdc. 2008.4597900

[20] S. Kim, "Cooperative game theoretic routing algorithm based on Shapley-value approach," in Proceedings of the $23 \mathrm{rd}$ international conference on Information Networking, Osaka, Japon, 2009.

[21] Y. Chao-hui, "Using Modified Shapley Value to Determine Revenue Allocation within Supply Chain," in International Conference on Information Management, Innovation Management and Industrial Engineering, Xi'an, China, 2009.

[22] D. H. Cui, L. Yao and R. Yang, "An algorithm for improving Shapley Value method for time claim in concurrent delay," in International Conference Logistics Systems and Intelligent Management, Harbin, China, 2010. https://doi. org/10.1109/iclsim.2010.5461055

[23] W. Xu, Z. Yang and H. Wang, "A Shapley value perspective on profit allocation for RFID technology alliance," in 11th International Conference on Service Systems and Service Management (ICSSSM), Beijing, China, 2014.

[24] F. J. Muros, J. M. Maestre, E. Algaba, T. Alamo and E. F. Camacho, "An algorithm with low computational requirements to constrain the Shapley value in coalitional networks.," in Control and Automation (MED), 2015.

[25] J. Castro, D. Gómez, E. Molina and J. Tejada, "Improving Polynomial estimation of the Shapley value by stratified random sampling with optimum allocation," Computers \& Operations Research, 2017. https://doi.org/10.1016/j. cor.2017.01.019

[26] D. G. Ramirez-Rios, N. Puello-Pereira, J. Ferro-Correa and S. Sankar Sana, "A cooperative game approach applied to the furniture supply chain of clusters for improving its competitive value: a case study," Control and Cybernetics, vol. 46 , no. 1,2016 . 